\title{
Histomorphological spectrum of neoplastic and non-neoplastic breast lesions -A two year study in a teaching hospital of North India
}

\author{
Honey Bhasker Sharma, ${ }^{1}$ Megha Bansal ${ }^{2, *}$, Nikhilesh Kumar ${ }^{3}$ \\ 1,2 Assistant Professor, ${ }^{3}$ Professor and HOD, Dept. of Pathology, TSM Medical College, Lucknow, Uttar Pradesh, India
}

*Corresponding Author:

Email: drmeghabansal1981@gmail.com

\begin{abstract}
Introduction: Lump in the breast is commonly encountered in the surgical clinics. Timely and accurate diagnosis of a breast lump can, not only prevent anxiety but also early intervention can be life saving. In India, breast cancer form the second most common malignancy after cervical cancer.

Objective: A retrospective study of 2 years duration was undertaken to determine the histopathological spectrum of breast lesions including both benign and malignant lesions.

Materials and Methods: The study was undertaken to know the histological spectrum of breast diseases of TSM medical college and hospital from 20 September 2016 to 20 September 2018. A total of 114 breast tissues sent for histopathology were studied.

Result: Out of 114 cases, benign lesions constituted 86\% (98 cases) and malignant lesions constituted $14 \%$ (16 cases). The commonest benign lesion was Fibroadenoma (51\% of all benign lesions) and the commonest malignant lesion was Infiltrating Ductal Carcinoma (62\% of all malignant lesions). Few uncommon lesions like Adenomyoepithelioma, flat duct aypia, atypical ductal hyperplasia and papillary carcinoma were detected.

Conclusion: Benign breast diseases are the commonest breast diseases in which fbroadenoma is the most common variety. Invasive Ductal carcinoma is the most common histological type of malignant tumor.
\end{abstract}

Keywords: Breast, Lump, Histological, Spectrum, Benign, Malignant, Ductal carcinoma, Fibroadenoma.

\section{Introduction}

Breast is a site of a broad spectrum of pathological alterations ranging from inflammatory lesions to life threatening invasive cancers. Breast lesions have gained global attention as breast cancer has become one of the leading causes of death among women all over the world. ${ }^{1}$ In India breast cancer is second most common cancer after cervical cancer but it is fortunate that the majority of the breast lesions in outpatient visits prove to have a benign pathology. ${ }^{2}$ The main purpose of this study is to analyse the spectrum of breast lesions in patients attending a new set up medical college and hospital at Amausi, Lucknow. No data regarding breast disease in this region is available as yet.

\section{Materials and Methods}

A retrospective descriptive analysis of all histopathologically diagnosed breast lesions including both benign and malignant, in women over 2 years from 20 September 2016 to 20 September 2018. The specimen was received in $10 \%$ buffered formalin and processed as per routine laboratory procedure, and then embedded in Paraffin for the preparation of blocks. The sections were stained with the $\mathrm{H} \& \mathrm{E}$ stains. The special stains were performed wherever required. The age, sex, clinical and histopathological features were recorded.

\section{Results}

During the period described, a total of 114 breast specimens were received. In all the breast lesions, the commonest presenting complaint was lump in the breast.
We received 11 mastectomies, 64 lumpectomies and 39 open biopsy specimens.

Among 114 cases, 98 cases (86\%) were benign and 16 cases $(14 \%)$ were malignant. Patients included in this study were from 11-80 years. Majority was in the age groups 20-30 years and all had benign breast disease. Age wise distributions of benign and malignant lesions are shown in the Table 1.

Table 1: Age distribution of benign and malignant breast lesions

\begin{tabular}{|l|c|c|c|}
\hline $\begin{array}{c}\text { Ages in } \\
\text { Years }\end{array}$ & Benign & Malignant & Total \\
\hline $11-20$ & 16 & - & 16 \\
\hline $21-30$ & 35 & - & 35 \\
\hline $31-40$ & 26 & 05 & 31 \\
\hline $41-50$ & 18 & 03 & 21 \\
\hline $51-60$ & 02 & 06 & 08 \\
\hline $61-70$ & 01 & 02 & 03 \\
\hline Total & 98 & 16 & 114 Cases \\
\hline
\end{tabular}

The majority of benign cases were fibroadenoma ( $51 \%$ of all lesions) followed up by fibrocytic disease of breast (16\% of all lesions). The youngest patient with fibroadenoma was 15 years old. Majority of fibroadenoma cases were seen in 21-30 years age. Majority of them showed slit like spaces on cut section. Intracanalicular and paracanalicular pattern were seen microscopically and in some both patterns coexisted in the same tumour.

Distributions of different benign breast lesions are shown in Table 2. 
Table 2: Distribution of different Benign Breast Lesions

\begin{tabular}{|c|c|c|c|}
\hline Type of Lesion & No of Patients & $\%$ Age Overall & \% Age of Benign \\
\hline Fibroadenoma & 50 & 44 & 51 \\
\hline Fibrocystic change & 16 & 14 & 16 \\
\hline Florid adenosis & 02 & 1.7 & 02 \\
\hline Galactocele & 02 & 1.7 & 02 \\
\hline Benign phyllodes & 03 & 2.6 & 03 \\
\hline Gynecomastia & 04 & 3.5 & 04 \\
\hline Adenomyoepithelioma & 02 & 1.7 & 02 \\
\hline Florid ductal hyperplasia & 03 & 2.6 & 03 \\
\hline Fat necrosis & 01 & 0.8 & 01 \\
\hline Fibroadenosis & 02 & 1.7 & 02 \\
\hline Breast Abscess & 03 & 2.6 & 03 \\
\hline Chronic granulomatous mastitis & 01 & 0.8 & 01 \\
\hline Flat atypia & 06 & 5.3 & 06 \\
\hline Atypical ductal hyperplasia & 03 & 2.6 & 03 \\
\hline Total & 98 Cases & $86 \%$ & $99 \%$ \\
\hline
\end{tabular}

Of all the cases, four were males and 110 were females. Male to female ratio was 0.03:1. All male breast lesions show gynecomastia, the youngest male with gynecomastia was 18 years old and the youngest female with fibroadenoma was 15 years old. Distribution of benign breast lesions according to age is shown in table 3. Rare cases of adenomyoepithelioma as shown in Fig. 1 were seen in age 41-50 years and flat duct aypia in ages 40-60 years as shown in Fig 2. Galactocele was seen in age 20-30 years as shown in fig 3. Phyllodes tumour was reported in one case of age $>60$ years as shown in Fig. 4

Table 3: Distribution of benign breast lesions according to age

\begin{tabular}{|l|c|c|c|c|c|c|}
\hline \multicolumn{1}{|c|}{ Lesion } & $\mathbf{1 1 - 2 0 Y}$ & $\mathbf{2 1 - 3 0 Y}$ & $\mathbf{3 1 - 4 0 Y}$ & $\mathbf{4 1 - 5 0 Y}$ & $\mathbf{5 1 - 6 0 Y}$ & $\mathbf{7 0} \mathbf{Y}$ \\
\hline Fibroadenoma & 12 & 22 & 12 & 4 & - & - \\
\hline Fibrocystic disease & 2 & 3 & 4 & 7 & - & - \\
\hline Galactocele & - & 2 & - & - & - & - \\
\hline Phyllodes Tumour & - & - & - & 2 & - & 1 \\
\hline Gynecomastia & 1 & 3 & - & - & - & - \\
\hline Adenomyoepithelioma & - & - & - & 2 & - & - \\
\hline Floridductal hyperplasia & - & - & 3 & - & - & - \\
\hline Fat necrosis & - & 1 & - & - & - & - \\
\hline Fibroadenosis & - & 1 & 1 & - & - & - \\
\hline Breast abscess & - & 2 & 1 & - & - & - \\
\hline Chr Granulomatous & - & - & 2 & - & - & - \\
\hline Flat atypia & - & - & 1 & 2 & 2 & - \\
\hline Atypical ductal hyperplasia & - & - & 2 & 1 & - & - \\
\hline Florid adenosis & 1 & 1 & - & - & - & - \\
\hline
\end{tabular}

Among the malignant neoplasm, invasive infiltrating ductal carcinoma (NOS) was the commonest (62.5\% of malignant lesions), maximally reported in ages $30-40$ years \& $50-60$ years. The youngest age for diagnosis of IDC was 36 years. As shown in the Fig. 5 we encountered only one case of papillary carcinoma as shown in Fig. 6 and one case of lobular carcinoma.
Distribution of different malignant breast lesions is sown in Table 4.

For histopathological grading, modified Bloom Richardsons system has been used which showed Grade 1(10\%), Grade 2(72\%), and Grade $3(18 \%)$.

Table 4: Distribution of different malignant breast lesions

\begin{tabular}{|l|c|c|c|}
\hline Type of lesion & Number of patients & Overall \% Age & \% Age of malignant \\
\hline Ductal carcinoma in situ & O4 & $3.5 \%$ & 25 \\
\hline IDC & 10 & $8.7 \%$ & 62.5 \\
\hline Lobular carcinoma & 01 & 1 & 6.2 \\
\hline Papillary carcinoma & 01 & 1 & 6.2 \\
\hline
\end{tabular}


Table 5: Age distribution of malignant breast lesions

\begin{tabular}{|l|c|c|c|c|c|c|}
\hline Lesions & $\mathbf{1 1 - 2 0 Y}$ & $\mathbf{2 1 - 3 0 Y}$ & $\mathbf{3 1 - 4 0 Y}$ & $\mathbf{4 1 - 5 0 Y}$ & $\mathbf{5 1 - 6 0 Y}$ & $>\mathbf{6 0 Y}$ \\
\hline DCIS & - & - & - & 1 & 2 & 1 \\
\hline IDC & - & - & 5 & 1 & 4 & - \\
\hline Lobular CA & - & - & - & 1 & - & - \\
\hline Papillary CA & - & - & - & - & - & 1 \\
\hline
\end{tabular}

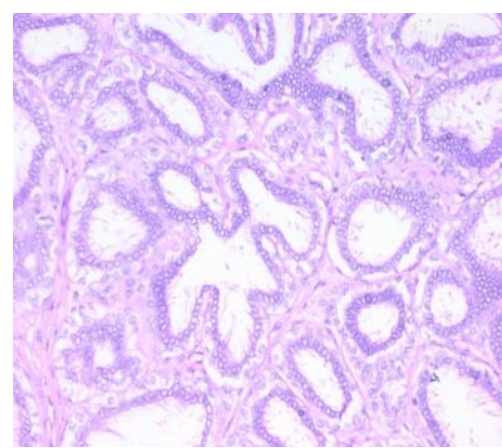

Fig 1: photomicrograph of adenomyoepithelioma

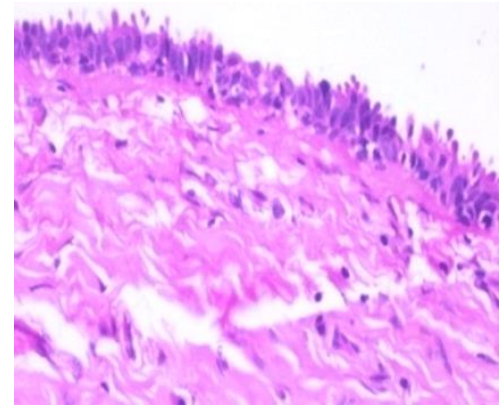

Fig 2: photomicrogragh of flat duct atypia

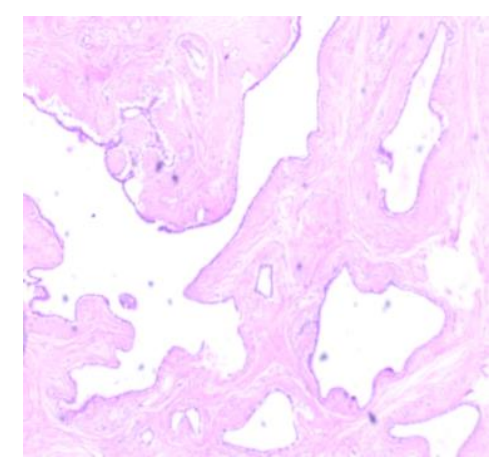

Fig 3: Photomicrograph of galactocele

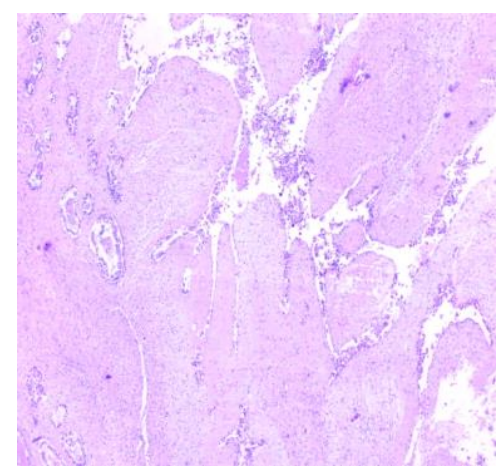

Fig 4: Photomicrograph of phyllodes tumour

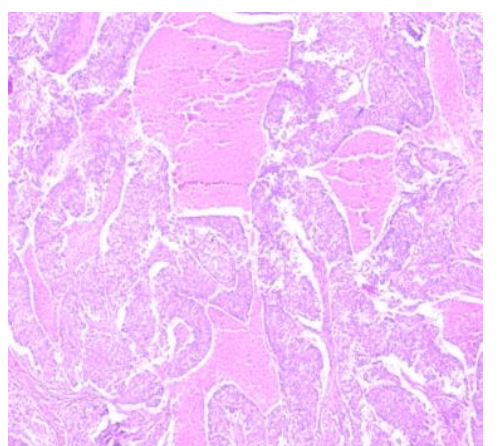

Fig 5: Photomicrograph of Infiltratin Ductal CA

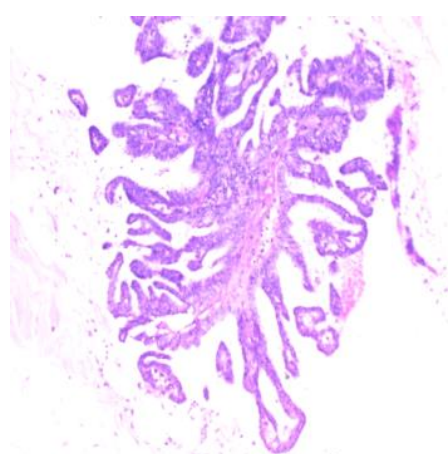

Fig 6: Photomicrograph of Papillary CA

\section{Discussion}

Incidence of benign breast lesions in the present study is $85.9 \%$ similar to study done by Vilasini Patil et al in 2017 who also got $85 \%$ of benign breast lesions in their study. ${ }^{1}$

In the present study fibroadenoma was the most common benign lesion $(51 \%)$ followed by fibrocystic change (16\%) and in a study done by Moolamalla Manasa Reddy et al the commonest benign lesion was fibroadenoma in $50.5 \%$ cases. $^{2}$

In the present study the most common male breast lesion was gynecomastia (4 cases) similar to study done by Geetanjali et al in 2015 where also gynecomastia formed the majority of the cases in males $(4 \%){ }^{3}$

The peak age of benign lesions is between 21-30 years and malignant lesion is between $30-40$ years and 50-60 years in our study similar to a study done by Kiran HS etal peak age of benign lesion is 21-30 years and malignant lesion is $31-50$ years. ${ }^{4}$

The malignancy rate in our study was $16 \%$ comparable to a study done by Mujahid Ahmad Mir et al in 2017 who reported $18.8 \%$ cases of malignancy. ${ }^{5}$

The commonest lesion was Infiltrating Ductal carcinoma in our study which constituted $62.5 \%$ cases of all malignant lesions. Similarly in a study by Vani 
Dayanand et al in 2015, IDC was the commonest malignant lesion obtained $(85.5 \%$ of all malignant lesions). ${ }^{6}$

Similarly Infiltrating Ductal Carcinoma was the commonest malignant lesions in a study done by Mayun AA et al. ${ }^{7}$ In the present study only four cases of DCIS were reported. Similarly in a study done by Abu Khalid Muhammad et al six cases of DCIS were reported. ${ }^{8}$

The most common grade among the invasive breast carcinoma was grade 2 in our study similarly in a study done by Vishal G Mudholkar et al the commonest grade was grade $2(58 \%){ }^{9}$

Our study comprises of one case of papillary carcinoma in the age 66 years similarly in the study done by Nazar Hussain et al in 2005 only one case of invasive papillary carcinoma was reported in their study in the age of 60 years. ${ }^{10}$

In a study done by Singh Thakur et al in 2000 where also IDC was the commonest malignancy $(81 \%){ }^{11}$

The peak incidence of infiltrating ductal carcinoma was $30-40$ years and $50-60$ years. Similarly in a study done by Gogoi et al two peaks of occurrence of malignant lesions were seen (i.e) $4^{\text {th }}$ and $6^{\text {th }}$ decades. ${ }^{3}$

Galactocele was reported in two cases in our study. In a study by Sanjay kumar C et al in 2017 reported a case of Galactocele in FNAC study. ${ }^{12}$

Benin phyllodes tumour were three in number in our study with a mean age of $40-50$ years. In a study done by Riffat Mehboob et al in 2018 reported 5 cases of phyllodes in a mean age of $46-55$ years. ${ }^{13}$

Chronic granulomatous mastitis was reported in our study in a 35 year female patient. In a study done by Chiragkumar L Prajapati et al in 2014 three cases of Tubercular mastitis were noted. ${ }^{14}$

Flat duct atypia was reported in 4 cases in our study, Study done by PMY Chan et al in 2018 reported flat duct atypia cases characterized by columnar cell changes where luminal epithelial cells are replaced by several layers of monomorphic cells with low grade cytologic atypia. ${ }^{15}$

Two rare cases of Adenomyoepithelioma in an age range of 40-50 years were noted. Similarly this rare case was reported by Bhasker Mitra et al in 2012 who described the tumour composed of biphasic proliferation of glandular epithelial cells and surrounding myoepithelial cells. Proliferative epithelial cells displayed tubular growth patterns .Prominent myoepithelial cells with clear cytoplasm surrounding the ductal epithelial cells were noted. Both epithelial and myoepithelial cells were blended without cytological atypia. ${ }^{16}$

\section{Conclusion}

Benign breast diseases are the commonest breast diseases in which fibroadenoma is the most common variety. Peak incidence of benign lesions in the age group of 21-30 years.

Invasive ductal carcinoma is the most common histoloical type of malignant tumour.Peak incidence of malignant lesions in the ages of 30-40years and 50-60 years.

\section{Conflict of Interest: None}

\section{References}

1. Patil V, Khandelwal A, Ghorpade G."Histopatholoical Spectrum of Benign Breast lesions". J Res Medi Dent Sci 2017;5(4):9-14

2. Reddy M, Kalahasti R. "Histopathological spectrm of Neoplastic and Non neoplastic breast lesions":A Two years study. Int J Sci Study 2017;4(11):158-62

3. Geetanjali G, Diganta B. "Histopathological Spectrum of Breast lesions -A Hospital based study." IJHRMLP 2016;2(1):73-8.

4. Kiran HS, Shetty J Rao C."Histomorphological Spectrum of Breast lesions". J Evolution Med Dent Sci 2016;5(54):3577-81.

5. Mir M, Manzoor F. "Histopathological analysis of breast lump in a tertiary care hospital". Int J Adv Res 2016;5(1):1334-37

6. Dayanand V, Shashidhar HB, Sandhya M, Ashwini NS, Bharathi M . "Spectrum of Breast neoplasms in Females: A 10 years Histopathological Review in a tertiary care Hospital." Int J Sci Study 2015;3(2):79-84.

7. Mayun AA, Pindiga UH, Babayo UD. "Pattern of Histopathological Diagnosis of breast lesions in Gombe, Nigeria." Niger J Med. 2008;17(2):159-62.

8. Maruf Raza A, Ahmed Z, Islam M. Arch Microbiol Immunol 2017;1(1):27-32.

9. Mudholkar V, Kawade S, Mashal S. "Histopathological study of neoplastic lesions of Breast." Indian Med Gazette 2012;353-64.

10. Hussain N, Ayaz B, Nadia N, Ali Z. "Pattern of female breast diseases in Karachi." Biomedica. 2005;21:36-37

11. Singh U R, Thakur A.N, Shah S.P, Mishra A. "Histomorpholoical Spectrum of Breast Diseases." J Nep Med Assoc 2000:39:338-41.

12. Chauhan S, Sarvaiya A.N. "Cytological and Histopathological correlation of breast lump:A 3 year study at Tertiary Care Center." Ann Pathol lab Med 2017;4(3):293-96.

13. Mehboob R, Perveen S, Ahmed N. "Spectrum of Benign Breast lesions in Tertiary Care Hospital of Lahore." Ann Kin Edward Med Uni 2018;(1):1-5.

14. Prajapati C, Jegoda R, Patel U, Patel J. "Breast Lumps in a Teaching Hospital :A 5 year study." Natl J Med Res 2014;4(1):65-67

15. Chan P, Chotai N, Lai E, Sin P, Chen J. "Majority of flat epithelial atypia diagnosed on biopsy do not require surgical excision." The Breast 2017;37:13-7.

16. Mitra B, Pal M, Saha T, Maiti A. "Adenomyoepithelial Adenosis of Breast: A rare case report". Turk patoloji Derg 2017;33:240-43.

How to cite the article: Sharma H.B, Bansal M, Kumar N. Histomorphological spectrum of neoplastic and non-neoplastic breast lesions -A two year study in a teaching hospital of North India. Arch Cytol Histopathol Res 2018;3(4):181-184. 